\title{
YouTube Videos on EFL College Students' Listening Comprehension
}

\author{
Chia-chi Chien ${ }^{1}$, Yenling Huang ${ }^{1} \&$ Peiwen Huang ${ }^{2}$ \\ ${ }^{1}$ Department of Applied Foreign Languages, Chung Shan Medical University, Taiwan \\ ${ }^{2}$ Department of Applied Foreign Languages, National Formosa University, Taiwan \\ Correspondence: Yenling Huang, Department of Applied Foreign Langauges, Chung Shan Medical University, \\ Taiwan.
}

Received: March 31, 2020

Accepted: May 18, 2020

Online Published: May 20, 2020

doi: 10.5539/elt.v13n6p96

URL: https://doi.org/10.5539/elt.v13n6p96

\begin{abstract}
This paper aimed to explore the effect of using YouTube as a supplementary material with EFL college students. The research intended to reveal the improvement of the students' listening comprehension after the 5-week treatments - students participating in this study are all Taiwanese, age from 18-20, with a high intermediate level of proficiency in English. They were all in the same class and were exposed under the multimedia (YouTube) learning environment. However, students were obliged to finish the pre-test and post-tests. Moreover, the questionnaire was offered to them in order to know the perceptions and reflections of students with integrating YouTube into courses as well.

In this research, paired T-Test was used to find out if there was a significant difference that exists before and after the treatments, also validate the pre-specified result. It was suggested that after training in the combination of the computer-assisted learning technique and traditional pedagogy, students performed better on the listening comprehension test than without the treatment before.
\end{abstract}

Keywords: the flipped classroom, Youtube videos, listening comprehension

\section{Introduction}

\subsection{Background}

YouTube, a popular video-sharing website, was created in February 2005 by Chad Hurley, Steve Chen, and Jawed Karim, the employees of PayPal. During the summer of 2006, YouTube became one of the fastest-growing sites on the World Wide Web, hosting more than 65,000 new video uploads. To one's surprise, YouTube achieved a milestone on October 9, 2006. It was announced that the company would be purchased by Google and would be completed on November 13.

Moreover, YouTube provides a wide variety of user-generated and corporate media videos. Due to its diversity and user-friendliness, it has been blowing up among people from the time forward. YouTube is a video repository that allows anyone with Internet access to view and upload videos free of charge. Hence, the viewing and production of videos boost prosperously in worldwide, making YouTube keep maintaining a secure foothold in the video-sharing market.

However, the emergence of this innovative website has dramatically transformed the way people live. The significant effect on people's lives is compelling. With the rapid development of technology and society, instruction must catch up with the pace of the ever-improving world. The utilization of media on education is escalating nowadays owing to temporizing the current situation.

From the traditional pedagogical way of SLA (Second Language Acquisition) to CAI (Computer-assisted instruction), the teaching methods and materials have been significantly changed and developed to foster the efficiency of learning. We have the reason to believe that by collaborating creative pedagogics and modern realia such as YouTube, it can supplement what traditional teaching methods lack, assisting the teacher in establishing a fresh and attractive learning environment; also examine the learning efficiency of students.

The paper aimed to compare the learning efficiency of traditional teaching materials and new learning resources - YouTube. Moreover, the purpose of this paper is to investigate whether students will have better listening comprehension after teaching in combination with YouTube or not. 
The study sought to answer the following questions:

(1) What's the preference of students between new learning resources and traditional materials?

(2) To what extent does the use of YouTube in the EFL classroom improve the listening comprehension and retention of EFL college students?

(3) To what extent does the use of YouTube in the EFL classroom affect the EFL college students' scores of GEPT official listening comprehension test?

\section{Literature Review}

\subsection{Computer-Assisted Instruction (CAI)}

Computer-assisted instruction which is also called "computer-aided instruction." Sinclair, Renshaw \& Taylor (2003) proposed that CAI has been shown to enhance rote memory skills and improve higher-order critical thinking skills. CAI is a modular supplementary tool that can be easily changed to meet individualized requirements and help teachers to build courses with integrity. It can be utilized to spur the motivation of students' learning autonomies, receiving feedback from students immediately, and monitoring the learning effectiveness of students in the meanwhile.

\subsection{The Importance of Listening Comprehension in SLA}

The importance of listening comprehension in SLA cannot be overemphasized. Mendelsohn (1994) defined listening comprehension as "The ability to understand the spoken language." Ahmadi (2016) also stated, "The ability to understand the spoken language has a vital role in second language learning and use. It is a necessary skill for classroom real communication activities and oral communication between native and nonnative speakers."

Rost (2002) proposed, "In Second Language Acquisition research, listening opportunities are often characterized as the "linguistic environment" - the stage for second language acquisition." The environment provides linguistic input in the form of listening and interaction opportunities embedded in social and pedagogical situations. The learner who eagers to acquire the second language must pay attention and understand the input from the target language speaker. As in first language acquisition, motivation and access to developmental opportunities are required. Listening comprehension is the process of understanding and awareness of spoken language.

\subsection{The Effect of Videos on Listening Comprehension}

People nowadays are accustomed to an ever-changing way of learning. As Al-Seghayer (2001) said, the adoption of computer technology in second language education is regarded as the most exciting development stemming from the participation of advanced technology in education. However, research conducted by Hamidi (2002) indicated that the audio-visual group performed better than audio-only groups on the post-test of the listening comprehension test. Thus, it can be inferred that audiovisual materials like videos can intensify the listening comprehension ability.

\subsection{Research Findings on the Use of YouTube in Education}

Many types of research have revealed that YouTube plays a crucial role in the educational field. Antonio \& Tuffley (2015) suggested that YouTube be just like a classroom in one's pocket. Terantino (2011) stated, "YouTube offers fast and fun access to language and culture-based videos and instruction from all over the globe." The ease-of-access and flexibility of YouTube act as a valuable tool that typically offers freely accessible content for anyone with an Internet connection. YouTube can also be considered to be a window that provides people with chances to view the world from a different perspective and broaden one's horizons.

\subsection{The Application of YouTube in SLA}

Arndt (2014) indicated that research on the Online Informal Learning of English has found that social media can facilitate language learning, mainly in the domain of vocabulary. Social media refers to any site that provides a network of people with a place to make connections, and YouTube is part of them.

Qiao (2016) said videos are always useful for explaining theories behind the phenomenon and make the explanation exciting and straight forward. We all know that making YouTube a language tool can prominently facilitate learning outcomes owing to its diversity and entertainment.

From the website: https://www.fluentin3months.com/youtube-language-learning/\#, Benny Lewis mentioned: "YouTube is an amazing tool for learning languages." He also pointed out 10 Ways to Use YouTube as a Language Learning Tool. For example, we can slow down the video when we have difficulty getting a picture of 
the contents. Moreover, we can easily find out the transcript then read what we are listening to. In this light, we can assure that YouTube is not only a handy language-learning tool but also a customized self-training platform.

\subsection{The Background of the Flipped Classroom}

The flipped classroom is an innovative way of instruction. This concept has come out from teachers called Jonathan Bergmann and Aaron Sams in the USA, 2007. Initially, they recorded the lectures and uploaded them on YouTube to help students make up the missing classes. Through inverting the classroom, students are allowed to learning by themselves online and have more time to interact with their teachers in the course. However, the essence of the flipped classroom is to make good use of the time of class and inspire students' motivations for self-education. Further, this instruction strategy can significantly increase the capability of higher-order thinking, which can deepen the extensity and intensity of learning.

When it comes to the development of the flipped classroom, Salman Khan is a significant driving force. He adopted the concept of distance-teaching and uploaded his videos on YouTube to help his relatives learn mathematics in the beginning. Afterward, his videos were widely-acclaimed and made this way of instruction much more accessible. The thrive of online teaching also urged him to establish his non-profit educational organization - Khan Academy. This organization has produced more than 5600 free short videos on YouTube nowadays. The contents of the videos are all-embracing, which provide people with the opportunity of learning in diversity.

\section{Methodology}

\subsection{Research Design}

This research aimed to evaluate the effect of YouTube videos on EFL college students' listening comprehension. A pre-test and the post-test (GEPT official listening comprehension test, form LTI-A) was utilized in this study to validate the learning efficiency. The students were all in one group. They were employed the treatment by using YouTube videos in their learning environment. The research design was carried out to all the subjects, and last for five weeks. Students have to do the pre-test and pro-test before and after treatment. Furthermore, they should finish the learning sheets each week and do the follow-up questionnaire as well after treatments.

\subsection{Participants}

The participants in this study were made up of 38 Taiwanese students who are about to take The General English Proficiency Test (GEPT), High-Intermediate Level. The range of their ages is from 18-20, with no gender limit. They speak Mandarin as their first language and should be equipped with a high intermediate level of proficiency in English, generally being able to use English in their daily lives.

\subsection{Instruments}

For the pre-test and post-test, it was the same listening comprehension test (Form HL-0001P;) offered by GEPT official website. The reliability of this test is 0.918 , which matched the official standard -0.85 . However, there are three parts of this test, which are Question and Statement Response, Conversation, and Short Talks. Each session of the test accounts for fifteen questions individually, constituting forty-five questions in total. Students are required to select one correct answer out of four choices after listening to the recording tape. Items will be spoken just one time.

For questionnaire (Question 1-10 on the questionnaire, see Appendix), which was adopted from "Teaching EFL to the iGeneration: A Survey of Using YouTube as Supplementary Material with College EFL Students in Taiwan." The questions were scored on a five-point Likert scale. Typically, in five-point Likert scaling, each item is scored on a five-point categorical scale, ranging from one extreme to the other (e.g., strongly disagree, disagree, undecided, agree, strongly agree), with these categories scored from one to five. Open-ended portions were existing in each of the questions which allow students to write down their comments or perceptions at will.

\subsection{Treatment}

The students were empowered to watch videos with visual aids on YouTube. All the course contents should be followed as a syllabus. In order to ensure the learning quality, students also had to finish the learning sheets each week.

However, the textbook was available to clarify the contents and evaluate the learning quality. The book of American SPEAK OUT, Upper-Intermediate, was used in this treatment as a textbook to augment the student's learning diversities. 


\subsection{Procedure}

At the beginning of 5-week treatments, students had to accomplish the pre-test in the first week. After the pre-test was executed, the teacher briefly introduced the syllabus of course contents and started the first-week scheduled courses synchronously. After the introduction was completed, the teacher followed the syllabus to impart knowledge of the courses weekly.

After the treatments, the students were given a post-test to gauge the learning efficiency. Moreover, a follow-up questionnaire were offered to the students.

\subsection{Data}

In order to distinguish the differences between before and after the treatments, T-Test was adopted to analyze the data of the research. There was also a questionnaire encompassing scoring rubric along with the post-test to assess the perception of the students of using YouTube in class.

Table 1. Flow Chart of Research Administration

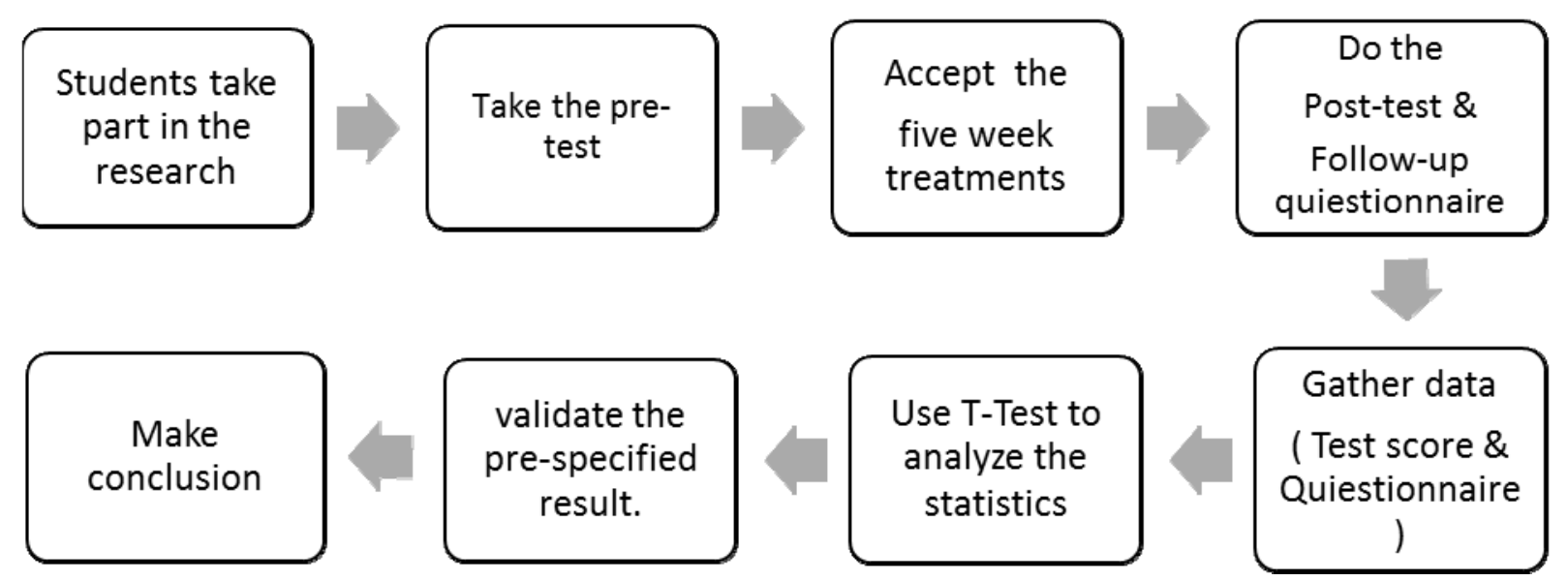

\section{Findings}

The results of the research were presented in this section. The statistics and the analysis of the pre-test and post-test showed that the use of YouTube in the EFL classroom indeed improved the listening comprehension and retention of EFL college students. Moreover, students' test scores were progressive averagely. That is, the pre-specified result was successfully validated.

However, the students' feedbacks were also provided in this section to show the perceptions and reflections of integrating YouTube in their English class.

Table 2. Descriptive Statistics of the comparison between Pre-and Post test

\begin{tabular}{ccclc}
\hline & Mean & $N$ & $S D$ & SD. Error Mean \\
\hline Pre test & 31.97 & 38 & 5.86 & .952 \\
Post test & 34.42 & 38 & 4.768 & .774
\end{tabular}

Based on table 2 above, the improvements in English listening skills was seen clearly. The Mean indicates that students can only pick 31 right answers out of 45 questions initially. However, after the 5-weeks treatments, students could more confidently choose the correct answers out of 45 items and got better scores.

Table 3. Paired Samples T-Test of the comparison between Pre- and Post-test

\begin{tabular}{ccccccccc}
\hline & & & \multicolumn{6}{c}{$95 \% C I$} \\
\cline { 3 - 8 } & Mean & St.D. & LL & $U L$ & Df & $t$ value & Sig. \\
\hline Pretest & 31.97 & 5.86 & & -3.707 & -1.188 & 37 & -3.937 & .000 \\
Postest & 34.42 & 4.76 & & & & & & \\
\hline
\end{tabular}


Table 3 presented that there were distinct differences between pre- and post-test because the result showed lower than the p.value 0.05 of the significance of tolerance. That is students who accepted the 5 -week treatments performed better than without the treatment.

Table 4. Students' perception toward integrating YouTube in the class (Captured from the Questionnaire)

7.Using YouTube material made class more interesting.

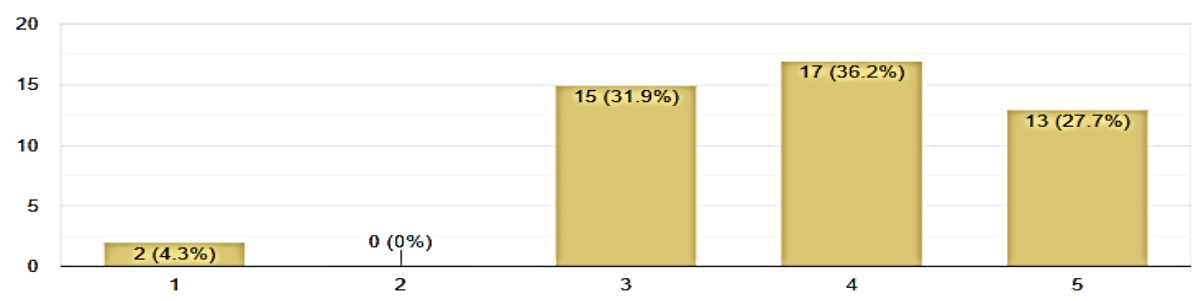

Table 5. Students' perception toward integrating YouTube in the class (Captured from the Questionnaire)

\section{Using YouTube in class has been beneficial to your English.}

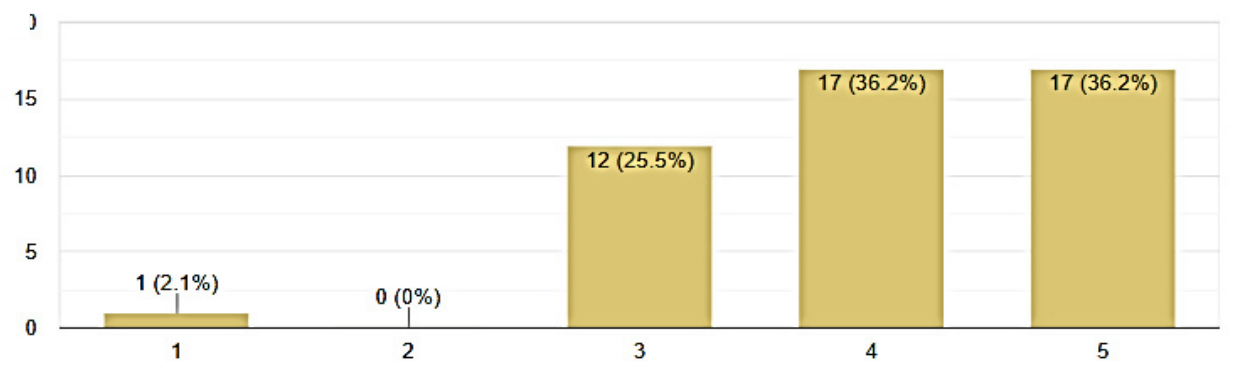

Table 6. Students' perception toward integrating YouTube in the class (Captured from the Questionnaire)

10. Using YouTube in class motivated you to study English.

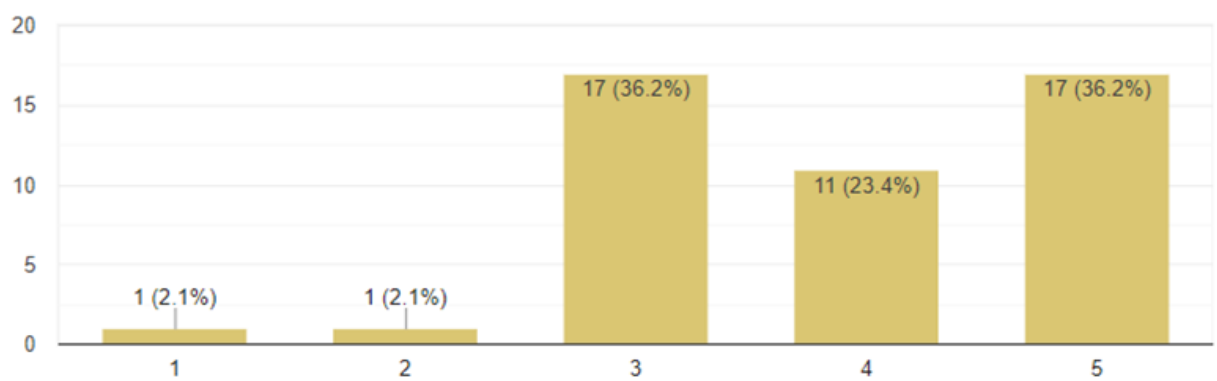

Tables 4, 5, and 6 showed that most of the students agreed that using YouTube in class made the whole course more exciting and had a significant influence on their English learning process. It can be stated that combining the computer-assisted learning technology - YouTube in class can not only help students improve their English skills but also activate their motivations. 
Table 7. The average score of each test on weekly learning sheets

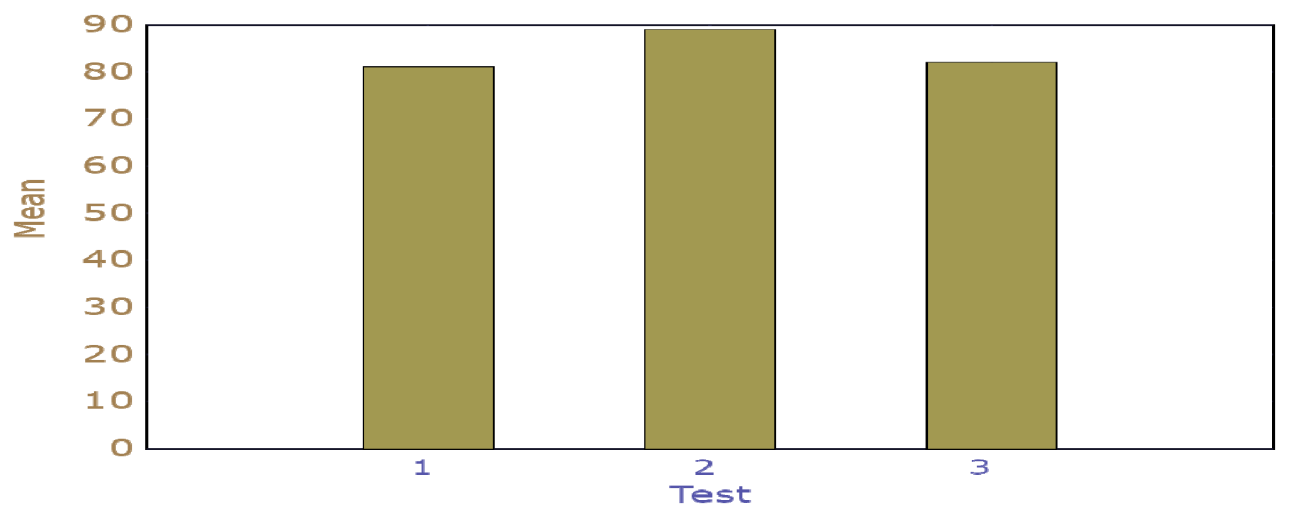

Based on the Table 7 above, it quickly proved that students always gave their full attention to the videos provided in the class so they can perform well on the test of weekly learning sheets. Namely, the effect of the treatments was undoubted.

\section{Discussion}

In response to the research question 1, the preference of students between new learning resources and traditional materials were investigated. Tables 4, 5, and 6 claims YouTube is a motivating learning tool to English learners that creates the exciting and interacting classroom environment. It can be stated that combining the computer-assisted learning technology - YouTube in class can not only help students improve their English skills but also activate their motivations. Student strong believed Youtube has a significant influence on their English learning process. Moreover, the use of YouTube in the EFL classroom improved the listening comprehension and retention of EFL college student. Table 3, showing the results of the post test after 5 weeks indicated Youtube teaching material enhance EFL learners' listening comprehension.

\section{Conclusion}

This study verified that YouTube indeed improved students' English listening comprehension. After accepting the treatments of the combination of YouTube and traditional pedagogy, students performed better than without the treatment before. Additionally, most of the students believed that YouTube is an excellent learning tool, and they were more willing to learn English with that convenient tool based on the positive feedbacks given by them.

Though the treatments only last for five weeks, the evaluation of the learning efficiency still could be seen. It implied that by combining YouTube with traditional teaching method could be powerful and useful. However, teachers still have to keep an eye on choosing the videos and control the proportion of the class design to ensure the best learning outcome.

\section{References}

Alhamami, M. (2013). Observation of Youtube language learning videos. Teaching English with Technology, 13(3), 3-17

Alqahtani, E. T. (2014). Effectiveness of Using YouTube on Enhancing EFL Students'

Bonk, C. J. (2011). YouTube Anchors and Enders: The Use of Shared Online Video Content as a Macrocontext for Learning. Asia-Pacific Collaborative education Journal, 7(1), 13-24

Burke, S.C. \& Snyder, S.L. (2008). YouTube: An Innovative Resource for College Health Education Courses. International Electronic Journal of Health Educaion, 11, 39-46

Kabooha, R. \& Elyas, T. (2018). The Effects of YouTube in Multimedia Instruction for Vocabulary Learning: Perceptions of EFL Students and Teachers. English Language Teaching, 11(2), p72-81. https/doi/10.5539/elt.v11n2p72

Kelsen, B. (2009). Teaching EFL to the iGeneration: A Survey of Using YouTube as Supplementary Material with College EFL Students in Taiwan. CALL-EJ ONLINE, 10(2). Retrieved from http://callej.org/journal/10-2/kelsen.html

Sinclair, K. J., Renshaw C.E. \& Taylor H.A. (2003). Improving computer-assisted instruction in teaching 
$\begin{array}{lllll}\text { higher-order } \quad \text { skills. } \quad \text { Computer } \quad \& \quad \text { Education, } & 42(2004), & 169-180 .\end{array}$ https://doi/10.1016/S0360-1315(03)00070-8

Snelson, C. \& Elison-Bowers, P. (2009). Using YouTube videos to engage the affective domain in e-learning. ResearchGate, 1481-1485. Retrieved from https://www.researchgate.net/publication/291157773_Using_YouTube_videos_to_engage_the_affective_do main_in_e-learning

Styati, E. W. (2016). Effect of YouTube Videos and Pictures on EFL Students' Writing Performance. Dinamika Ilan, 16(2), 307-317

Watkins, J. \& Wilkins, M. (2011). Using YouTube in the EFL Classroom. Language Education in Asia, 2(1), 113-119. https://doi.org/5746/LEiA/11/V2/I1/A09/Watkins_Wilkins 


\section{The Questionnaire of Students' Perspectives of YouTube}

This questionnaire is for research purposes only. All data will be aggregated and will not be used to evaluate you, your grade, or your teacher.

\section{Demographic}

1. What is your gender?

_ Female__ Male

2. Do you have access to a computer with a high-speed connection outside of class?

_ Yes__ No

3. Have you used YouTube before?

_Yes__ No

4. How often do you use YouTube outside of class? (often, not very often, very often)

5. When you use YouTube on your own, what do you usually use it for? (You may choose more than one answer) Entertainment Education Studying English Others

6. You think watching YouTube improves your Listening Speaking Reading skills. (You may choose more than one answer)

\section{Please Check the Score One to Five on the Following Items.}

1- Strongly disagree; 2 -Disagree; 3- Neither agree nor disagree; 4- Agree; 5- Strongly agree.

7.Using YouTube material made class more interesting. 12345

7-1. Please state why or why not "using YouTube material made class more interesting."

8.The YouTube material used was relevant to what was studied in class. 12345

8-1. Please state why or why not "the YouTube material used was relevant to what was studied in class."

9. Using YouTube in class has been beneficial to your English. 12345

9-1. Please state why or why not " using YouTube in class has been beneficial to your English."

10. Using YouTube in class motivated you to study English. 12345

10-1. Please state why or why not "using YouTube in class motivated you to study English."

11. Using YouTube in class motivated you to use it yourself to study English outside of class? 12345

11-1. Please state why or why not " using YouTube in class motivated you to use it yourself to study English outside of class."

Thank you very much for taking the time to fill out this survey.

\section{Copyrights}

Copyright for this article is retained by the author(s), with first publication rights granted to the journal.

This is an open-access article distributed under the terms and conditions of the Creative Commons Attribution license (http://creativecommons.org/licenses/by/4.0/). 